\title{
Designing with Dignity: Health and Design Research for Underserved Communities
}

\author{
Yvonne Michael, Diana Nicholas
}

\begin{abstract}
Designing with Dignity" is a course that examines how Health and Design research can inform problem-solving for underserved communities. The educational arm of the new Center for Health in the Designed Environment (CHDE) received a foundation grant for a course entitled "Health and Design Research: Designing with Dignity" that was piloted spring 2016. In this pilot, students from multiple disciplines examined the relationship between the built environment, health and behavioral health issues. The course linked these issues with the over-arching theme of housing insecurity. Within this central theme, the students were particularly concerned with underserved groups who may be suffering poor health outcomes due to their lack of access to safe and healthy living spaces. Frameworks within the course exposed the students to multi-level social determinants of behavioral health for underserved groups. Students then learned techniques to innovate solutions for these groups that would improve their limited access to housing resources. Taught by faculty from health and design, this curriculum is designed to help students ask questions and create solutions. They engage in a process that centers on melding human-centered design approaches with public health research. The course participants are taught to create fresh solutions that will have positive impacts on behavioral health in the urban environment.
\end{abstract}

Keywords: health and design research, human-centered design, interdisciplinary education, underserved communities, housing insecurity 
At Drexel University, "Health and Design Research: Designing with Dignity" is a new course that examines how design and health research informs problem-solving and the development of appropriate solutions for underserved communities facing complex problems. Predicated on creating a process for strengthening the relationship between the built environment, health, and behavioral health issues, the course creates opportunities for developing new solutions to urban housing insecurity. Focused on interdisciplinary education and pedagogy, the instructors created a process that melded social determinants of health frame-works and design thinking techniques with the central theme of safe living environments and access, or housing insecurity. The students in the course were particularly focused on solutions for underserved groups who may be suffering poor health outcomes due to their lack of access to safe and healthy living spaces. Housing insecurity is defined as high housing costs in relationship to income, or insufficient quality or access by the Department of Health and Human Services. ${ }^{1}$ Underserved groups are defined through cultural and socioeconomic status and can differ regionally. ${ }^{2}$ The main pedagogical goal was to examine multi-level social determinants of behavioral health for underserved groups and then innovate access-based solutions for these groups using processes that would draw on students' up-close explorations. The goal was to combine these viewpoints and develop ideas that would improve the residents' and urban dwellers' limited access to housing resources. The thesis of this paper, and the pedagogy presented, is that the interdisciplinary linkage of health research and design process will create new ways of thinking and unique inter-professional experience in both disciplines. Designed to help students ask the right questions for successful problem solving, the pedagogy centers on creating new solutions that would have positive impacts in the urban environment.

This course is a central part of the mission of the Center for Health \& The Designed Environment (CHDE), and was developed in partnership with the Scattergood Foundation, a local behavioral health foundation. An interdisciplinary center comprised of university faculty from Interior Design, Public Health, Engineering, and Science, Technology \& Society, the mission of CHDE is to address urban inequities through new health and design research. Selected through a competitive application process in 2015 to become one of the inaugural cohorts of the American Institute of Architects' Design \& Health Research Consortium, (AIA Consortium) the group works to advance research centered on the designed environment and related health outcomes. CHDE works to develop a shared multi-disciplinary research process that builds on the strengths and expertise of all disciplines and informs practice in design and public health. The educational arm of CHDE received a foundation grant for the course and it was piloted in spring 2016. In this article, we examine how transdisciplinary exploration and identification of meaningful guiding frameworks from each discipline informed the design and implementation of the course in support of the thesis stated above. At the same time, we will describe our team process and the development of 
initiatives in education, research, and outreach in the urban community. The paper will also examine the ways that multi-disciplinary collaboration can inform educational initiatives to ensure that social determinants of health drive informed design in the built environment. The future plans for the design challenge and the course will also be described here.

\section{SCATTERGOOD AND DESIGN CHALLENGE BACKGROUND}

The "Designing with Dignity" course and program were funded and collaboratively developed with a local and regional Philadelphia nonprofit, The Scattergood Foundation. The mission of Scattergood is guided by the belief that behavioral health is the cause of many larger societal problems. A philanthropic, grant-making foundation, they advocate for improving the behavioral health system in the Philadelphia region by funding projects that change how behavioral health is viewed and practiced. The foundation was named after Thomas Scattergood, a nineteenth century Quaker minister who protested the deplorable conditions and treatment of the mentally ill. An early patients' rights advocate, Scattergood played a vital role in advancing the moral treatment for those unable to advocate for themselves. His work was partially responsible for the advances in mental health treatment and the founding of the nation's first private psychiatric hospital. Foremost in Scattergood's mission and that of the hospital he inspired was the idea of treating those suffering from mental illness with dignity and respect, a new concept at that time. ${ }^{3}$

Thomas Scattergood's vision for fair treatment of society's most underserved constituents is part of the Scattergood Design Challenge, an annual competition that allows people from all backgrounds and experiences to submit new ideas for complex social problems where previous, traditional solutions have proven ineffective. Hosted in conjunction with Drexel University's Dornsife School of Public Health, the Scattergood Design Challenge provided a platform to create new ideas for previously unsolved problems as well as funding, press exposure, and collaboration opportunities with various community organizations, for the winning solution. ${ }^{4}$ In past years the design challenge has been run through the efforts of Scattergood staff and School of public health interns. The course described here builds on the successful foundation of that partnership.

\section{COURSE DIRECTION AND GOALS: HEALTH AND DESIGN RESEARCH FOR INNOVATION}

In today's educational environment, it is increasingly recognized that students must be trained to understand and use multiple disciplinary viewpoints as a way of accessing problem solving. ${ }^{5}$ The Association of Schools and Programs of Public Health have recently endorsed four core competencies for interprofessional education: values and ethics for interprofessional practice, roles and responsibilities, interprofessional communication, and 
teams and teamwork. ${ }^{6}$ Created for students to examine and experience interdisciplinary problem solving and problem-solving applications in different disciplines, the course framework was informed by these core competencies. The students worked in teams and overtly discussed the ethics of each situation. Social determinants of health, or the features in underserved groups setting (outside of genetics or biology) that shaped their likelihood of disease, ${ }^{7}$ are especially helpful in creating the kinds of open discussion that facilitated the students in building a clear and up-close understanding of the problems, challenges and solutions. "Designing with Dignity" created an original framework based on participatory research and thinking for problem solving; punctuated by public health best practices and design-based empathy building.

The course practices included the "Double Diamond Method" in which students work iteratively to brainstorm and apply both divergent thinking and convergent thinking in their work. This model is referred to in design thinking literature, including Nigel Cross' seminal book Design Thinking: understanding how designers think. ${ }^{8}$ Divergent thinking is defined as being able to develop many solutions to a problem; convergent thinking is identifying the links between these quick solutions and synthesizing sound and original ideas from them. Drawing heavily on criticality and synthesis deployed at the right junctures in the process, convergent thinking can give meaning to initially simple ideas. ${ }^{9}$ Here, issues and problems are framed through informed perspectives that come from "deep dives" or participatory interactions with the communities. ${ }^{10}$ In using the deep dives and divergent and convergent thinking, students started to explore an empathy for their group that led to original insights. Students then re-visited the social determinants of health framework to inform empathy building with their communities. Using divergent thinking they itemized their deep dive information, then used the convergent technique of affinitizing the information in order to generate human centered ideas that were drawn from their experience with the users. One example of this from the class could be found in the work of the group examining LGBTQ youth issues. This group found that mobility and anonimity were two major needs for LGBTQ youth, stemming from their experiences with abuse and bullying. Through interviews with care and service providers to this community and some observations of the community themselves, solutions that would honor those needs were then brainstormed and included a new web resource that is at the same time crowd-sourced and privately accessed.

\section{PEDAGOGICAL APPROACH AND PROCESS}

\section{Social Determinants of Health as Engine for Change}

The course began with an introduction to the concepts of social determinants of health, social gradient, and health inequity. Briefly again, the social determinants of health are the factors in the social environment (outside of genetics or biology) that shape the burden of disease. ${ }^{11}$ For example, 
social determinants of health include the environments and settings in which people are born, live, work, and age. These environments and settings are influenced by economics, social policies, and politics. The larger theoretical model involves multiple layers of influence ranging from the individual biology to individual behaviors to social and community networks (including family and neighbors), to socioeconomic, cultural and environmental conditions (such as housing, work environment, education, water and sanitation). The idea of social gradient is that the patterning of health occurs across the entire socioeconomic spectrum. ${ }^{12}$ In other words, no matter where a person is on the social ladder, those people who are higher fare better in health outcomes than those who are below them. Finally, health inequities are avoidable inequalities in health between groups of people. For example, the gap we see in longevity when comparing higher income countries to lower income countries or within a country like the United States, the gap we see between African Americans and white Americans. ${ }^{13,14}$

These concepts are fundamental to understanding the role of the built environment, including housing, on mental and physical health. To apply these concepts, the class participated in a "But Why" activity. ${ }^{15}$ The goal of the activity was to think about the social determinants of health inequities to get to the cause of a problem. For the activity, we used the example that the prevalence of asthma among children living in public housing is double the national prevalence of all children. ${ }^{16}$ Then we asked the students "Why?". They began to identify things like mold and dust. Next, we asked the group to consider "But Why?" They identified poor building maintenance and lack of knowledge. Then we again asked, "But Why?" Eventually, after several rounds of questions, we got beyond the immediate causes of ill health began to talk about issues such as local and state policies that affect the housing options that are available to people and that inform the planning of public housing projects. After this kick-off, we introduced the students to IDEO's HumanCentered Design (HCD) Toolkit, the main design framework for this course. The Scattergood Foundation intially drove their internal process through the framework set forward in Jeanne Leitdka and Tim Ogilvie's guide Designing for Growth: the four questions for innovation. These four questions define how one might examine a problem to gain original and innovative thinking and solutions. The four questions are: What is?; What if?; What wows?; and What Works? ${ }^{17}$ By funneling the idea generation process through the four steps of the Design Thinking Framework, the original Scattergood group invited the public to develop not only new ideas to solve society's health problems but new ways of thinking about health. The course built on that foundation with additional best practices in design thinking that were drawn from multiple sources.

\section{Design Problem Solving and Human Centered Processes}

IDEO's Human-Centered Design (HCD) Toolkit is a 101 page, step-bystep, e-book outlining the elements to Human-Centered Design -an 
international innovation process created by IDEO in collaboration with IDEO, Heifer International, and ICRW that is responsible for innovations such as the HeartStart defibrillator and the Red Cross Blood Donor System. Human-Centered Design allows students to use a style of idea generation where they "hear" the needs of residents in new ways, "create" innovative solutions to meet those needs, and "deliver" financially sustainable solutions. ${ }^{18}$ In addition to the methods outlined in the HCD Toolkit, the curriculum also walked students through the previously mentioned four steps of Design Thinking: What is? What if? What wows? What works? ${ }^{19}$ By designing the curriculum around two innovation methods with parallel frameworks, and with grounding in social determinants of health theory, students were able to gain a thorough understanding of some of Philadelphia's most pressing social and health problems. They could then generate unique solutions to those problems, and internalize a framework for innovating in the future. The more dynamic sessions where the ones in which students were challenged to think divergently and suspend their critical mind. They had to approach the material in a fresh way and were not allowed to presuppose the workability of suggested solutions.

\begin{tabular}{|l|}
\hline $\begin{array}{l}\text { Question 3: please state the most important thing you have learned about working in teams } \\
\text { so far }\end{array}$ \\
\hline Answer: Learning the research process and how they differ in respective fields \\
\hline Answer: collaboration \\
\hline $\begin{array}{l}\text { Answer: be positive and be active and communicate with other people actively and say whatever you } \\
\text { want to say }\end{array}$ \\
\hline $\begin{array}{l}\text { Answer: Patience and motivating each other collaboration with other discipline give wider } \\
\text { perspective. }\end{array}$ \\
\hline $\begin{array}{l}\text { Answer: It is much easier when the focus is on the process and not the final product. It easier to work } \\
\text { as a team than as individual parts of a whole. }\end{array}$ \\
\hline Answer: To express is very important, whether it is a question or an idea, we have to speak it out. \\
\hline Question 4: How have your group skills changed? \\
\hline Answer: being able to think both critically and in design across studies \\
\hline Answer: More inclined to participate and take the lead at some times \\
\hline $\begin{array}{l}\text { Answer: I have become more aware of how important simple group discussion is; we have reached } \\
\text { most of our major conclusions simply by having dynamic conversations }\end{array}$ \\
\hline Answer: As we start to work together, it is also important to build respective and friendly atmosphere \\
in the group.
\end{tabular}

Table 1. This table shows questions and responses form course evaluations. Note the emphasis on learning to work together, students admit it is not always easy but that it adds to their skills. 
Students began the course with preliminary research into some of the more complicated and multifaceted housing issues that affect underserved communities. This led students to understand better how the built environment can have disproportionately adverse effects on the health of low-income individuals and families. Based on their findings, students formed research teams comprised of two interior design students and two public health students. Each of the teams began an initial "deep dive" into available research to identify a knowledge base in their areas of interest. With areas of research defined, students began preparing for the "hear" phase of the HCD framework by finding target populations, choosing interview methods and strategies, and identifying stakeholders. With this information and professor feedback, students began conducting interviews with their identified target populations, and presented their findings in a "deep dive" report, outlining existing scientific knowledge, populations/ individuals interviewed, methods used, and significant findings. The group studying the needs of women with children found themselves faced with much new data after their observational deep dive. They were invited to observe an onsite meeting at a local facility. In hearing what the mothers had to say about their living struggles, they concluded that the women needed more extensive ways to integrate their case management. Could they become their own case managers? What type of design project could support such a finding? This group refined their problem statement through their deep dive experience.

Next, with a substantial understanding of the problems they were attempting to solve, the class moved into the "Create" phase of the HCD model and began to brainstorm possible solutions while reviewing data and identifying challenges faced by users. Students were asked to utilize multiple brainstorming techniques, including the Triz Method of Creative Destruction which involves gaining perspective on a problem through comparing it to the worst case scenario. ${ }^{20}$ In addition, we deployed a "How Might We" exercise and the FDV (Feasibility, Desirability, and Viability) assessment. In this model where Feasibility, Desirability, and Viability overlap, successful solutions can be found. ${ }^{21}$ These two exercises were conducted in class through having interchange between established groups to lend outside perspectives on ideas and assumptions. All of these techniques allowed for the suspension of criticality in idea generation, the exchange of multiple ideas in a group setting, and various allowances for assessment and reinvention of solutions. In the final stages of the course, students were given various materials to make and present prototypes of their solutions. The course culminated with students "delivering" their final prototypes utilizing the Mini Pilot method-a technique that identifies simple, low-investment next steps before making large, full-scale investments - via one minute, single video pitches. ${ }^{22}$

This year, the group solutions, some of which are mentioned above, include: a website to network LGBTQ youth to safe situations; a gallery 
owned and run by single mothers who could then leverage that business into a livelihood for their families; an at-home asthma robot that could detect the relative safety of living conditions for those with asthma; a food access job training truck for homeless; and a resource for disabled students to travel more independently through campus housing. Each of the groups followed the process and each uncovered unexpected solutions along the way. The asthma group started by studying how air quality affected housing insecurlty. This group linked health issues with housing issues through user and expert interviews. They found that resources to understand this problem were scarce. Families were often in the dark as to how to track the treatments for the asthma-based conditions that arose from the urban indoor and outdoor air pollution in the city environment. The asthma group, as they were now called, developed the idea of a robot who could act as a health advisor, caseworker and adminstrator. It could track treatment, and educate the child on how to properly take the medicine while entertaining at the same time. For young asthma patients, this was identified as an important need that such an innovation could fulfill through both expert interviews and user research. Figure 1 shows an early prototype for the robot on the right.

By utilizing the HCD model-a model based on the constant exchange and revamping of ideas with a variety of constituents-a community of innovators was created in the classroom that extended to the community outside of the classroom that students were innovating for. In putting the end user at the center of the design process, students were able to establish human connections that went beyond a computer screen or a textbook. Taking a broad view of the relationships between health, behavioral health, and issues in the living situation, the course was grounded in multi-disciplinary problem seeking and question making to examine complex challenges with a new perspective. In synthesizing their deep dive research, the students also created a variety of personas to describe the types of users for whom they might design solutions, and these personas led to a reframing of the initial design questions for each team. The personas for each group dug deep into the needs of the groups and were a way of framing those needs in an understandable profile. Groups also engaged in a series of iterative problem-solving sessions derived from exposing ideas to repeated discussion, reframing, brainstorming, and finally, testing against their knowledge. They also tested ideas through the lens synthesized and promoted by IDEO, a wellknown human-centered design firm: feasibility, desirability, and viability. ${ }^{23}$ The students used these tools to work iteratively and test their ideas.

\section{Building a New Community in the Classroom}

One important element in the course that was essential for success was the intentional building of community among the course participants. A number of different approaches were used to build 


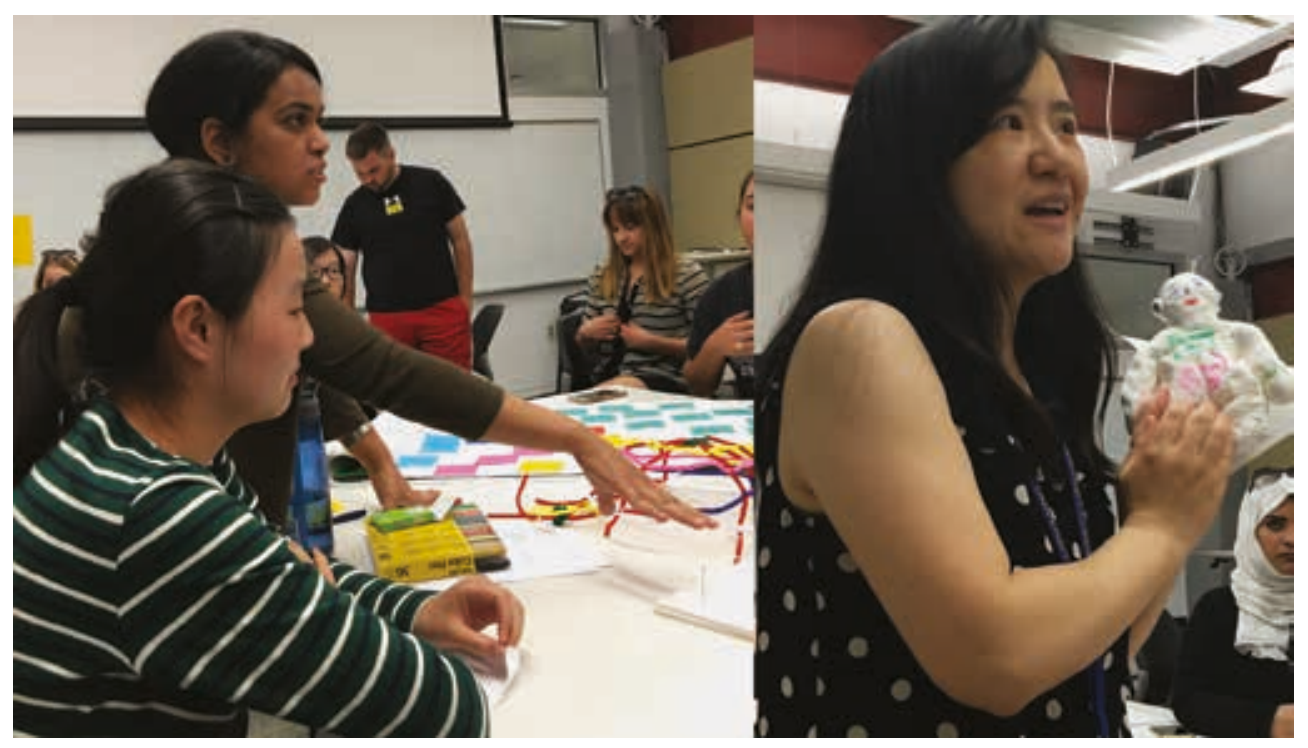

Figure 1. Students presenting and discussing their initial prototypes.

community. Students were asked to take meals together on a regular basis, the class itself had a weekly pizza dinner for the first part of the term that created outside-of-class conversations. Another approach was a "wagon wheel" activity in the first class. Based in processes learned through the "Inside-Out" educators training program at Graterford prison, the wagon wheel is a community participatory process. In this exercise, the group arranges itself in an inner and outer wheel, these two wheels rotate in relationship to each other stopping and creating small group discussions every 90 seconds around a given topic. ${ }^{24,25}$ The wagon wheel builds empathy and group understanding and can uncover unexpected connections between seemingly unconnected participants.

Another community-building technique was the implementation of an on-going opening round or community meeting held at the beginning of most class periods. In the opening round, the class sits in a circle, and everyone in the circle responds to a question. For example, after we read a chapter in Evicted by Matthew Desmond, ${ }^{26}$ class participants were asked to reflect on what factors kept one of the key figures in the book from finding a different (more affordable) place to live. ${ }^{27}$ For the opening round, students are often asked to check in with how they feel about a relevant topic or share a personal perspective with the group when appropriate to the process. Additionally, students were intentionally placed into mixed discipline groups early in the course (in the second week) and participated in guided activities with their group each class period. Anecdotal feedback from the participants included surprise and fascination with each others' disciplines and excitement at collaborating in a meaningful way. 


\section{COURSE THEMES: URBAN HOUSING AND INEQUITIES}

How do you design a course to involve students from multiple disciplines in a process to address complex societal issues, and give students a perspective on the problems society faces through the lens of health and design thinking? Faculty worked to create an informed cycle in the class and the groups worked in class on modeled process. Student groups then were expected to deploy those processes outside of class without guidance. The faculty developed a mode of design research and thinking paired with a public health perspective in which both frameworks were revisited along the way. The students were pushed to deploy these frameworks on their own outside of class whenever possible. Initially, the funding foundation and the faculty collaborated to identify the topic for the students in the course to study. Criteria included topics that would allow some flexibility and at the same time unify the class around issues of health, mental well-being and equity. Housing and the lack of access for underserved groups, when examined in some detail, proved to be a topic that will define the urban condition for the foreseeable future, and unify multiple disciplines.

Housing insecurity leads to poor health outcomes, and public health and housing sectors often do not collaborate to solve these issues. Stress created through insecure housing access is a major contributing factor to the ill health of underserved urban residents. Housing costs are so high for many urban dwellers that they are unable to afford preventative doctor visits or preventative health measures. ${ }^{28}$ Emerging mega-regions and urbanization have created changes in the housing market and new levels of housing deficiencies, including not enough affordable units for lower income renters; compromised units; and rising rates of lower income renters in the face of these shortages. These issues create new problems for lower-income families in retaining their homes. The class cohort was introduced to these evolving developments in both public health and design to change the system through novel thinking.

The report "Beyond Health Care: New Directions to a Healthier America" examines housing inequities and how they link to infection, disease and problematic childhood development. ${ }^{29} \mathrm{High}$ blood pressure and diabetes are linked to the emotional stress of housing insecurity. ${ }^{30}$ Rapid urbanization leads to deteriorating health among the least advantaged of our population. Some federal policies have had a ripple effect on the availability of affordable housing in our modern cities and the attendant health of urban dwellers. These recent policies, which include financing policies, are connected to segregation and the creation of sprawl in the suburbs. Creating financial stress for low-income families, high housing costs reduce pre-tax income and difficulty in affording necessities. ${ }^{31}$ In planning the course, it was agreed that there was strong evidence that housing access and reliability is a topic that can touch on health, design, and behavior. Significant overlap between the ongoing research practices 


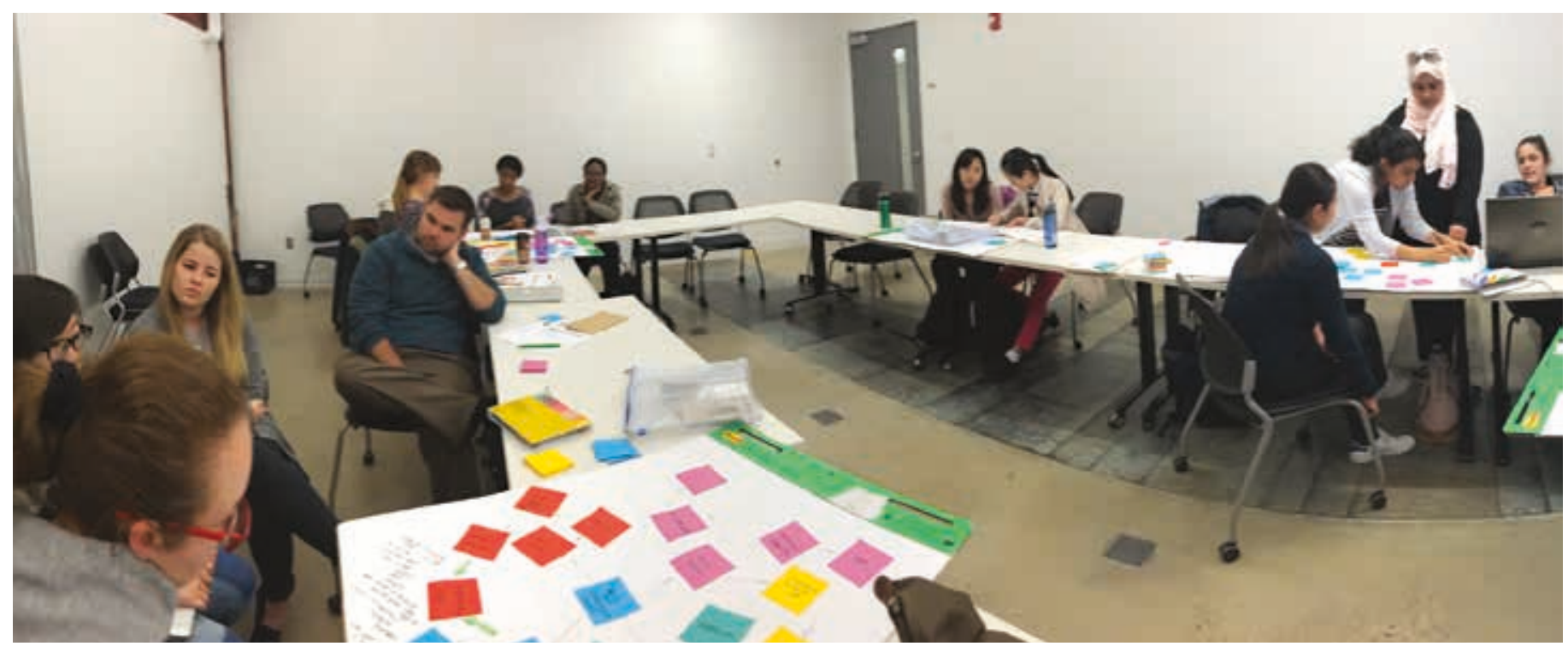

Figure 2. Students working collaboratively on HCD methods.

of each faculty member in the course, and the chosen topic, enabled a situation where faculty experiences would allow the course to be enriched.

\section{CONCLUSIONS}

\section{Course Outcomes and Student Discoveries}

Participation in the course was designed so that the students were able to examine and experience interdisciplinary problem-solving processes. In this first iteration, students reviewed and discussed the possible application of these methods across their respective disciplines. The class collectively was exposed to participatory research and thinking for problem-solving through the techniques described here for building community and empathy. The group deployed, with gusto, the idea of getting close to the users and truly trying to understand their situation to build design empathy. Creative brainstorming techniques including affinity matrices created an understanding of the challenges faced by these underserved groups in maintaining a stable housing situation. Students then went through a process of iteration and collaborated to come up with original solutions they could attempt to test and understand. The core competencies stated above, the students values and ethics for interprofessional practice, roles and responsibilities, interprofessional communication, and teams and teamwork were discussed and re-enforced as part of the course process. ${ }^{32}$ The course incited the students to progress their skills in design thinking and ethical design but the subtler skills related to core competencies were also developed. Through both space and place based solutions, drawn from the students' self driven team work, the teams built empathy and understanding between their disicplines and experiences as well. 
Recent research links housing insecurity to the prevalence of poor urban health including heart and respiratory-related morbidity. ${ }^{33}$ Design and public health have both acknowledged that the complexity of these problems call for new solutions beyond what one discipline may produce. ${ }^{34}$ As a cross-listed course in the School of Public Health and the Department of Architecture, Design \& Urbanism at Drexel University, "Designing with Dignity" allowed students to collaboratively study and understand several underserved groups and their relationship to housing. This area of study is one that neatly overlaps both disciplines and created many opportunities for the core competiencies metioned above to be developed. The cohort created unique synergies that are more than both disciplines could create working independently. Outcomes include the development of realistic solutions that could later be prototyped in more detail through the design challenge. See Figure 2 for images of the groups working to produce and present their outcomes. In working together to develop shared design and health expertise to take back into their respective professions, the cohort has undoubtedly improved their future practices. Students were also asked to enumerate their new approaches to problem-solving and collaboration in the anonymous course evaluations. The table below shows that they had responses in line with the learning priorities for interdisciplinary learning stated above.

\section{Design Challenge Future}

The value of the informed design loop in which research and exposure to users can drive innovation has had an impact on the students in the class and faculty. We hope this course will be a model for inter-professional courses at the intersection of design and health. Here, students explored concepts and methodologies of design, health research, design thinking and human-centered issues. The outcomes were deemed unusual, and successful by all involved. In the Fall of 2016, The Scattergood Foundation agreed to an expansion of the course and funding into a three year-long cycle program for behavioral health innovation. Intended to take the place of their existing design challenge, this course will become the linchpin of a yearlong health and design research process in which students and faculty will work to create, prototype and present similar solutions that can be brought forward and developed in the real world. The goals of The Scattergood Foundation and the Center for Health in the Designed Environment align and we are pleased to expand this partnership for Health and Design to make a difference in the urban environment. 


\section{Notes}

1. Diana Becker Cutts et al., "US Housing Insecurity and the Health of Very Young Children," American Journal of Public Health 101, no. 8 (August 2011): 1508-14. 2. Tracy A. Weitz, Karen M. Freund, and Leslie Wright, "Identifying and Caring for Underserved Populations: Experience of the National Centers of Excellence in Women's Health," Journal of Women's Health \& Gender-Based Medicine 10, no. 10 (December 2001): 937-52, doi:10.1089/152460901317193521.

3. "Legacy I Scattergood Foundation," http://www.scattergoodfoundation.org/legacy\#.WHOkxVMrLBQ.

4. "What Is a Scattergood Design Challenge? I Scattergood Foundation," http://www.scattergoodfoundation.org/what-scattergood-design-challenge\#.WHTylLYrLeQ. 5. Simone V. Gill et al., "The Importance of Interdisciplinary Research Training and Community Dissemination," Clinical and Translational Science 8, no. 5 (October 2015): 611-14, doi: 10.1111/cts.12330.

6. "IPEC-2016-Updated-Core-Competencies-Report_final_release_.pdf," https://ipecollaborative.org/uploads/IPEC-2016-Updated-Core-Competencies-Report final release.PDF.

7. Richard G. Wilkinson and Michael Gideon Marmot, "Social Determinants of Health: The Solid Facts." (World Health Organization, 2003).

8. Nigel Cross, Design Thinking: Understanding How Designers Think and Work (Oxford, UK and New York: Berg, 2011).

9. Ibid.

10. IDEO, Human-Centered Design Toolkit: An Open-Source Toolkit To Inspire New

Solutions in the Developing World, $2^{\text {nd }}$ edition (Palo Alto CA, USA: IDEO, 2011), 15.

11. Michael Marmot, "Social Determinants of Health Inequalities," The Lancet 365, no. 9464 (March 19, 2005): 1099-1104, doi:10.1016/S0140-6736(05)71146-6.

12. Richard G. Watt, "Strategies and Approaches in Oral Disease Prevention and Health Promotion," Bulletin of the World Health Organization 83, no. 9 (September 2005): 711-18, doi: $10.1590 /$ S0042-96862005000900018.

13. Wilkinson and Marmot, "Social Determinants of Health."

14. Marmot, "Social Determinants of Health Inequalities."

15. "Chapter 17. Analyzing Community Problems and Solutions I Section 4. Analyzing Root Causes of Problems: The 'But Why?' Technique I Main Section I Community Tool Box," in Community Tool Box, http://ctb.ku.edu/en/table-of-contents/analyze/analyze-communityproblems-and-solutions/root-causes/main. The Community Tool Box is a public service developed and managed by the University of Kansas (KU) Work Group for Community Health and Development and partners nationally and internationally. The Tool Box is a part of the KU Work Group's role as a designated World Health Organization Collaborating Centre for Community Health and Development.

16. Dogu Brugge et al., "Comparison of Multiple Environmental Factors for Asthmatic Children in Public Housing," Indoor Air 13, no. 1 (March 1, 2003): 18-27, doi:10.1034/ j.1600-0668.2003.01130.x.

17. Jeanne Liedtka and Tim Ogilvie, Designing for Growth: A Design Thinking Tool Kit for Managers (New York: Columbia Business School Publishing, 2011), kindle loc. 509.

18. Ibid.

19. Ibid.

20. Keith McCandless and Henri Lipmanowicz, "Liberating Structures - 6. TRIZ," http://www.liberatingstructures.com/6-making-space-with-triz/.

21. IDEO, Human-Centered Design Toolkit, 7.

22. Ibid., 141-143.

23. Ibid., 7.

24. "Inside/Outside Circles - The Teacher Toolkit,"

25. "The Inside-Out Center I Graterford Think Tank,"

http://www.insideoutcenter.org/think-tank-graterford.html.

26. Matthew Desmond, Evicted: Poverty and Profit in the American City (New York: Crown Publishers, 2016).

27. Matthew Desmond and Rachel Tolbert Kimbro, "Eviction's Fallout: Housing, Hardship, and Health," Social Forces 94, no. 1 (2015): 295-324. 
28. "Beyond Health Care," RWJF (Robert Wood Johnson Foundation), April 1, 2009, http://www.rwjf.org/en/library/research/2009/04/beyond-health-care.html.

29. "Beyond Health Care," RWJF (Robert Wood Johnson Foundation), April 1, 2009, http://www.rwjf.org/en/library/research/2009/04/beyond-health-care.html.

30. Gary G. Bennett, Melissa Scharoun-Lee, and Reginald Tucker-Seeley, "Will the Public's Health Fall Victim to the Home Foreclosure Epidemic?," PLOS Med 6, no. 6 (June 16, 2009): e1000087, doi:10.1371/journal.pmed.1000087.

31. Judith Yates and Vivienne Milligan, "Housing Affordability: A $21^{\text {st }}$ Century Problem," AHURI Final Report No. 105, Australian Housing and Urban Research Institute Limited, Melbourne, https://www.ahuri.edu.au/research/final-reports/105.

32. "IPEC-2016-Updated-Core-Competencies-Report_final_release_.pdf."

33. Desmond and Kimbro, "Eviction's Fallout."

34. Patricia O'Campo, "Are We Producing the Right Kind of Actionable Evidence for the Social Determinants of Health?," Journal of Urban Health 89, no. 6 (June 15, 2012): 88193, doi: 10.1007/s11524-012-9695-5.

\section{References}

Bennett, Gary G., Melissa Scharoun-Lee, and Reginald Tucker-Seeley. "Will the Public's Health Fall Victim to the Home Foreclosure Epidemic?" PLOS Med 6, no. 6 (June 16, 2009): e1000087. doi: 10.1371/journal.pmed.1000087.

"Beyond Health Care." RWJF (Robert Wood Johnson Foundation), April 1, 2009. http://www.rwjf.org/en/library/research/2009/04/beyond-health-care.html.

Brugge, Dogu, Jose' Vallarino, Luke Ascolillo, Neal-Dra Osgood, Suzanne Steinbach, and John Spengler. "Comparison of Multiple Environmental Factors for Asthmatic Children in Public Housing." Indoor Air 13, no. 1 (March 1, 2003): 18-27. doi: 10.1034/j.1600-0668.2003.01130.x.

"Chapter 17. Analyzing Community Problems and Solutions I Section 4. Analyzing Root Causes of Problems: The 'But Why?' Technique I Main Section I Community Tool Box.” Community Tool Box. http://ctb.ku.edu/en/table-of-contents/analyze/analyze-communityproblems-and-solutions/root-causes/main.

Cross, Nigel. Design Thinking: Understanding How Designers Think and Work. Oxford (UK) and New York: Berg, 2011.

Desmond, Matthew, and Rachel Tolbert Kimbro. "Eviction's Fallout: Housing, Hardship, and Health." Social Forces 94, no. 1 (2015): 295-324.

Gill, Simone V., Misha Vessali, Jacob A. Pratt, Samantha Watts, Janey S. Pratt, Preeti Raghavan, and Jeremy M. DeSilva. "The Importance of Interdisciplinary Research Training and Community Dissemination." Clinical and Translational Science 8, no. 5 (October 2015): 611-14. doi: 10.1111/cts.12330.

IDEO. Human-Centered Design Toolkit: An Open-Source Toolkit To Inspire New Solutions in the Developing World. $2^{\text {nd }}$ edition. Palo Alto CA (USA): IDEO, 2011.

"Inside/Outside Circles - The Teacher Toolkit." http://www.theteachertoolkit.com/index.php/tool/inside-outside-circles.

"IPEC-2016-Updated-Core-Competencies-Report_final_release_.pdf." https://ipecollaborative.org/uploads/IPEC-2016-Updated-Core-Competencies-Report final release. PDF.

"Legacy I Scattergood Foundation." http://www.scattergoodfoundation.org/legacy\#.WHOkxVMrLBQ.

Liedtka, Jeanne and Tim Ogilvie. Designing for Growth: A Design Thinking Tool Kit for Managers. New York: Columbia Business School Publishing, 2011.

- - - . Designing for Growth: A Design Thinking Tool Kit for Managers. New York: Columbia Business School Publishing, 2011.

Lipmanowicz, Keith and Henri McCandless. "Liberating Structures - 6. TRIZ." http://www.liberatingstructures.com/6-making-space-with-triz/.

Marmot, Michael. "Social Determinants of Health Inequalities." The Lancet 365, no. 9464 (March 19, 2005): 1099-1104. doi: 10.1016/S0140-6736(05)71146-6.

Murphy, Kelly, Patrick Fafard, and Patricia O'Campo. "Introduction-Knowledge Translation 
and Urban Health Equity: Advancing the Agenda." Journal of Urban Health 89, no. 6

(May 15, 2012): 875-80. doi: 10.1007/s11524-012-9693-7.

O'Campo, Patricia. "Are We Producing the Right Kind of Actionable Evidence for the Social Determinants of Health?" Journal of Urban Health 89, no. 6 (June 15, 2012): 881-93. doi: 10.1007/s11524-012-9695-5.

Pollack, Craig Evan and Julia Lynch. "Health Status of People Undergoing Foreclosure in the Philadelphia Region." American Journal of Public Health 99, no. 10 (October 2009): 1833-39. doi: 10.2105/AJPH.2009.161380.

"The Inside-Out Center I Graterford Think Tank." http://www.insideoutcenter.org/think-tank-graterford.html.

Watt, Richard G. "Strategies and Approaches in Oral Disease Prevention and Health Promotion." Bulletin of the World Health Organization 83, no. 9 (September 2005): 711-18. doi: 10.1590/S0042-96862005000900018.

"What Is a Scattergood Design Challenge? I Scattergood Foundation." http://www.scattergoodfoundation.org/what-scattergood-design-challenge\#. WHTyILYrLeQ.

Wilkinson, Richard G. and Michael Gideon Marmot. "Social Determinants of Health: The Solid Facts." World Health Organization, 2003.

Yates, Judith, and Vivienne Milligan. "Housing Affordability: A 21 ${ }^{\text {st }}$ Century Problem," AHURI Final Report No. 105, Australian Housing and Urban Research Institute Limited, Melbourne, https://www.ahuri.edu.au/research/final-reports/105.

\section{Acknowledgments}

This course and project are funded by The Scattergood Foundation, with special thanks to the following: Debra Ruben, Alyson Ferguson, Caitlin O’Brien, Joe Pyle.

Yvonne Michael received her ScD in Epidemiology and Health and Social Behavior from the Harvard School of Public Health, SM in Health and Social Behavior from the Harvard School of Public Health and BA in Government from the College of William and Mary. Dr. Michael's research is focused on three primary areas: active aging, women's health, and health disparities. The unifying theme across these research areas is the use of epidemiology as a method of inquiry to identify social characteristics of communities and individuals and describe the impact of these factors on population health.

E-mail: ylm23@drexel.edu.

Diana Nicholas has a focus, in both research and teaching, on speculative design research and tools for the design of healthy urban spaces in underserved communities with an emphasis on the residential interior. With a research driven collaborative and mentorship approach, Dee's work includes novel biophilic design, human-centered design thinking processes, interior materials, visualization and advances in building science within the urban home. As a speculative design researcher, Dee believes that informed design and trans disciplinary collaboration is at the heart of novel advances and improvements in the built environment. She is the Director of the MS Design Research program, and holds a Bachelor of Architecture from Carnegie Mellon University, an MFA from The University of the Arts, and a certificate in Health and Design from Cornell University.

E-mail: dsn35@drexel.edu. 
